Original Articles :

\title{
Rorschach, Culture and Popular Responses
}

\author{
Shweta, Sengar, K. S., Bajpai, R. C., Singh, A. R
}

\begin{abstract}
ABSTRAC
Researches investigating cross-cultural and ethnic group differences on projective tests are relatively scarce. However, significant differences in relation to acculturation, socialization, and the very different cultural subgroups process cognitively and emotionally, had documented. A number of studies have shown that popular responses are associated with cultural background, which is likely to reflect common contribution of the group. This study provides information on how Indian adult non patients' gives variety of popular responses on the Rorschach test administered and scored by following Beck system. The present research is an effort to generate normative data for proper responses in Indian context.
\end{abstract}

Key words : - Rorschach, Popular response, cultural, cultural free, cross-culture

\section{Introduction:}

Human being can be described as a culture-building species. No human have ever survived and perpetuated themselves except as members of social group. Thus, the study of personality should be done in context of one's culture. In this, regard Benedict (1934) says that no man ever looks at the world with pristine eyes. He sees it edited by a definite set of customs and institutions and ways of thinking. Anthropologist had carried out many crosscultural studies on Rorschach. About eighty years ago, Benedict (1934) and Hallowell (1934 cited that the crosscultural researcher must have an intimate knowledge of the culture as a whole; researcher must also be aware of the normal range of individual behaviour within the cultural pattern and likewise understand what the people themselves consider to be extremely deviated deviations from this norm.

Boyer (1988). De Vos \& Boye, (1989). and Mattlar and Fried (1993) presented a large-scale normative study in Finland and concluded; at least as concerns Europe and the U.S., it would seem that the principle elements of the structural summary could be described as 'sturdy', little affected by nationality. Normative studies of Finland and other Scandinavian countries describes that "Christmas elves" are most frequent response on card II and it is coded as popular (Mattlar \& Fried, 1993). Should there be cultures in which such cultural-specific responses as "Christmas elves" occur frequently.
Although the use of several of these tests with diverse groups may be controversial (Frank, 1994, HaleBenson, 1982; Worchel, 1997). they have been used crossculturally, without standardized modification. According to Anastasi (1998). personality projective techniques present a peculiar discrepancy between research and practice. When formally evaluated as psychometric instruments, many of the commonly used projective tests as the Rorschach found technically lacking with people of colour, yet the major differences among ethnic group has been documented on instruments such as the Rorschach (Jones, 1978; Kaplan, 1961).

Many critics in the respect of cultural influence have attacked the test. Garcia (1981). Green and Griffore (1980) commented that the standard test, when it comes to content, modality and structure has certain biasness. That further led to a blind alley in its application and interpretation. When it applied with population, whose culture linguistic, economic or social background is different gives an inappropriate result.

The Rorschach is assumed culture- free or at least culture -fair. This means that the test can applicable to any cultural. Since it is content free test as this is "unstructured" in nature it is assumed that subject's responses represents his or her unique response rather than a response to any common meaning the test may have. However, both of these assumptions have been in contrast by several studies (Jaleel, 1990). Takahashi and 
Zax (1966) compared American and Japanese college students to examine the stability of meaning of the Rorschach for the two groups. They found the cultural variables resulted in a greater number of significant differences between the Japanese and American subjects than one's mental health. Rabin and Limuaco (1967) found the evidence that the meaning of Rorschach differed quite significantly between these two cultures.

Greenfield (1997) maintained that cross-cultural misdiagnosis and incorrect assessment often occurs when examiner from a dominant cultural group and respondent from a less powerful group using instruments that developed in the dominant culture. (Banks, 1997; Frank, 1994; Obiakor, Algozzine, \& Schwenn, 1995). Multicultural researchers are familiar with diversity of cross-cultural affect. It is also known that the any assessment tool is developed in a specific cultural and generalised on group of peoples who belongs to that particular cultural so any approaches cannot be applied blindly to people of different cultural (Jones, 1978; Lonner, 1985; Russell, Fujino, Sue, Cheung, \& Snowden, 1996). Additionally, the validity and reliability of a test used with peoples of different cultures who were not part of the standardization group are questionable. It is also important to recognize that diversity may exist between examiners and examinees even when the difference may not be readily apparent. So far, the study on projective technique as we have, indicates that there are variations in person-to-person responses in any given culture (Lindzey, 1961). He further state that following the factor which contribute in giving the responses as follows:

The social class, ethnic group, cultural background, their past life experience and coordination with given situation.

Another, issue which is repeatedly addressed in literature is psychological normality is an absolute or relative phenomenon. A successful adaption always counts with a particular personality characteristics. It is observed that both absolute and relative perspectives on abnormality contribute to reasonable conclusions. Jonathan Swift (1726/1960) gives a classic example in this regard, "Gulliver was too big for the Lilliputians and too small for the Brobdingnagians".

Maturity, adjustment and maladjustment are depended upon the certain personality characteristics, which learnt from his own culture, followers of this notion, assumed that Rorschach sets certain standards of maturity and adjustment. This view in its maximum, demonstrates ethnocentricism. A minimum expression of this standpoint would be that the Rorschach could be an indicator of closeness of internal imbalance, which would cause problems in whatever social environment. Thus, the question raised that internal imbalance and immaturity that has been grown up in specific cultural can be casually applicable for another culture.

De Vos, et.al. (1989) studied Japanese "normal" families and families with delinquent teens. They noted higher levels of denial and lower levels of $\mathrm{H}$ and $\mathrm{M}$ in delinquent families, especially to Card III. Japanese as a group gave fewer responses, put more work into integrating them $(\mathrm{W}>\mathrm{D}$ and $\mathrm{Zd}$ higher). and while they gave as many and most of the same popular, for Card VIII they saw a flower in the centre, an uncommon American response. If Rorschach variables do tap into defensive processes, then the defences of a "normal" and "delinquent" family might both differ from American samples, and so distinctions between A and B (like M and C) on the Rorschach here may not hold up in other countries. They found most of the popular were the same, and found significance for ideas behind $\mathrm{M}$ and $\mathrm{C}, \mathrm{T}$ and $\mathrm{Y}$, as well as trends for significance for V. While delinquent families did not give more aggressive responses, such as those in America do, they gave fewer positive and healthy content responses, more isolated, dysphoric, and evasive (maps and islands) responses, and few positive authority content (badges, helmets, and crests). reports of "playing" between people, and fewer symbols of aesthetic value (vases, chandeliers, etc).

\section{Method:}

In present study the sample size consisted of 530 respondents with equally distributed gender from the capital of India. The respondents were selected on the basis of stratified systematic random sampling method. The Age range of respondents included in the study was 20 to 30 years, educated up to high school and not having any physical or psychological illness at the time of interview. The subjects having positive family history of mental illness were excluded from the sample. Descriptive statistics were used to analyse the data.

Data were coded, entered and analyzed using SPSS package (version 16.0) and presented in percentage. Chisquare test was used for evaluating association between gender and socio-demographic characteristics and t test / Mann-Whitney $U$ test was used to establish the relationship between two genders and different variables of Rorschach. 'P' value for the level of significance was calculated and the same less than 0.05 was considered. 


22. Kumar, P. (1961). The Rorschach test in some mental -disorder-schizophrenic group. Psychology, 4,36-40.

23. Klopher, B., Ainsworth, M.D., Klopher , W.G., (1954). Developments in the Rorschach Technique. II: Fields of Application. Yonkers, New York: World Book Company.

24. Lindzey, G., (1961). Projective Techniques and Cross-Culture Research. New York: AppletonCentury-Crofts.

25. Lonner, W. J. (1985). Issues in testing and assessment in cross-cultural counseling. The Counseling Psychologist, 13, 599-614.

26. Mattlar, C-E., \& Fried, R., (1993). The Rorschach in Finland. Rorschachiana, 18, 105-125.

27. Mc Call., R.J.,\& Doleyes, E. J., (1955). Popular responses on the Rorschach test in relation to the number of responses. Journal of Clinical Psychology, 11, 300-302.

28. Obiakor, F. E., Algozzine, B. \& Schwenn, J. (1995). Where are we in educating African American students with problem behaviours? Western Journal of Black Studies, 19 (3).Fall, 203-210.

29. Prabhu, G. G. (1967). The Rorschach technique with normal adult Indians. Indian Psychological Review. 3, 97-105.

30. Rabin, A.I.,\& Limuaco, J.A., (1967). A comparison of the connotative meaning of Rorschach's inkblots for American and Filipino college students. Journal of Social Psychology, 72,197-203.

31. Russell, G. L., Fujino, D. C., Sue, S., Cheung, M. K., Snowden, L. R. (1996). The effects of therapistclient ethnic match in the assessment of mental health functioning. Journal of Cross-Cultural Psychology, 27, 5, 598-615.
32. Sendin, C., (1995). Nonpatient transcultural comparison. In Proceedings Book, 14th International Congress of Rorschach and Projective Techniques (p.207-212). Lisbon, Portugal :Gulbenkian.

33. Singh, D.K., Singh, A., \& Singh, A.R., (2004). Relevance of Beck norms of Rorschach inkblot technique on Indian population-an exploratory pilot study on normal subjects; SIS J. Proj.Psy.\& Ment. Health, 12, 49-52.

34. Takahashi, S., \& Zax, M., (1966). The stimulus value of Rorschach inkblots: a comparison of Japanese and American students. Japanese Psychological Research, 8, 38-45.

35. Worchel, F. (1997). Personality Assessment in the Schools. In Gutkin \& C. Reynolds (Eds.). Handbook of School Psychology. New York, NY: Wiley.

Authors:

1. Shweta, Assistant Professor, Psychology, National University of Study \& Research in Law, Ranchi

2. K.S. Sengar, Additional Professor, Clinical Psychology, RINPAS, Ranchi

3. R. C. Bajpai, Assistant Professor, Biostatistics, Army College of Medical Science, Delhi

4. A.R. Singh, Professor \& Head, Department of Clinical Psychology \& Director, RINPAS, Ranchi.

Correspondence Address :

Dr K S Sengar, Additional Professor, Department of Clinical Psychology, RINPAS, KANKE, Ranchi.

Email: achyutsengar9@gamil.com 